\title{
On the relationship between linguistic intelligence and recalling lexical items in SLA
}

Shakouri, Nima

Roudbar Islamic Azad University, Roudbar, Iran (Shakouri.ni@gmail.com)

Sheikhy Behdani, Reihaneh

Department of English Translation, Lahijan Branch, Islamic Azad University, Lahijan, Iran (Reihaneh.sheikhy322@gmail.com)

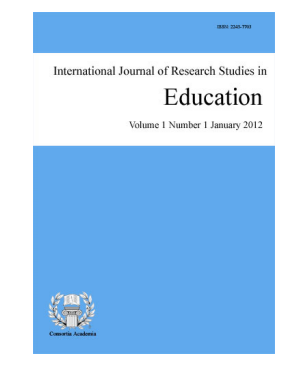

ISSN: $2243-7703$ Online ISSN: 2243-7711

Teimourtash, Morteza

OPEN ACCESS

Department of English Translation, Shahr-e-Qods Branch, Islamic Azad University, Tehran, Iran

(Teimourtashmorteza20@yahoo.com)

Received: 9 September $2016 \quad$ Revised: 27 September $2016 \quad$ Accepted: 14 October 2016

Available Online: 2 November $2016 \quad$ DOI: $10.5861 /$ ijrse.2016.1644

\section{Abstract}

This study was carried out to investigate the possible relationship between linguistic intelligence and recalling lexical items in second language acquisition (SLA). In this regard, 40 participants (22 females and 18 males) took part in the current study. To measure the participants' linguistic intelligence scores, the researcher used McKenzie's (1999) questionnaire. A cued-recall vocabulary test was also designed to measure the participants' recalling of lexical items in L2. Regression analyses demonstrated that the participants' linguistic intelligence did have a significant correlation with the participants' recalling of lexical items in L2.

Keywords: linguistic intelligence; multiple intelligence; recall 


\section{On the relationship between linguistic intelligence and recalling lexical items in SLA}

\section{Introduction}

The second half of 20th century is the age of individualism that individual values and differences are respected (Akbari \& Hosseini, 2008). In a sense, "individualism offers true independence, equality and freedom, with the most noble attempt to freely give each individual the highest and the most complex knowledge available" (Ponderator, 2007, p. 10). Part and parcel of individualism is the notion of simplicity. Ponderator goes on to hold that simplicity in a system is more efficient than complexity since it does not lead to corruption. Meanwhile, although all systems to some extent possess complexity, individualism, per se, minimizes this to an extreme extent.

Compatible with the tenets of individualism, each individual has a different composition, and different intelligences are located in different areas of the brain and can either work independently or together (Gardner, 1999). Gardner defines intelligence as a combination of psychological and biological characteristics that enable individuals to solve problems. Elsewhere, Gardner (1983) contends that each individual has a multitude of intelligences that are quite independent of each other.

The notion of individualism in language acquisition inspires the fact there exist individual differences in female and male brain structures. Thereupon, the present researchers will face an even more intense debate over what these differences involve. In effect, the ability of the brain to recall lexical items in L2 is stemmed in the notion of individualism. Recalling lexical items in L2 is prone to a variety of influences. In this regard, the present study endeavors to investigate whether participants' linguistic intelligence has any relationship with recalling lexical items in L2 or not.

\section{Literature review}

Success in life depends on understanding our own intelligence profile (Hassaskhah, 2009). Sternberg (1984) defines intelligence as mental activity directed toward purposive adaptation to, selection, and shaping of real-world environment relevant to one's life. According to Sternberg, successful intelligence is composed of three factors: (1) analytical intelligence (i.e., the ability to solve problems), (2) creative intelligence (i.e., the ability to deal with the new situation using past experiences and current skills), and (3) practical intelligence (i.e., the ability to adapt to a changing environment).

In Vygotsky's (1978) theory of social mediation, intelligence is also a function of activity that is mediated through tools. Along the same vein, according to Piaget (1963), intelligence is an adaptation, wherein knowledge is constructed through the two complementary processes of assimilation (i.e., the process of incorporation) and accommodation (i.e., the process of modifying existing mental structures so that new information can fit in them). In sum, Piaget defines intelligence as developmentally constructed in the mind of the learner and moves from concrete to abstract stages of understanding. However, there is no consensus among scholars regarding the definition of intelligence. Ellis (2008) defines "intelligence [as] the general set of cognitive abilities involved in performing a wide range of learning tasks" (Ellis, 2008. p. 649). Brown (2000) asserts that the greatest barrier to SLA is a matter of memory. In a sense, if you are capable of remembering just everything you have ever heard, you will succeed in SLA. Research conducted by Genesee (1976) show that intelligence is highly correlated with the performance of learners in L2 reading, grammar, vocabulary, while it is unrelated to speaking abilities (Genesee, 1976). Still, according to several scholars (e.g., Tanzeel, 2010), the influence of intelligence on the development of communicative competence is disrespected.

Although the notion of general intelligence (i.e., $\mathrm{G}$ factor) has long been supported by psychologists (Spearmen, 1909), it was later replaced by multiple intelligences raised by Gardner (1983). Gardner's multiple 
intelligence theory is deeply rooted in cognitivism. As Hassaskhah (2009) asserts, the implications of Gardner's theory can be explicitly employed in learning and teaching. She holds that if an individual is susceptible to spatial or musical intelligence, for instance, they should be reinforced to develop the very abilities. Helping teachers and learners realize that there are multiple ways to learn contributes to the efficiency of their orientation in SLA. Hassakhah hypothesizes that by emphasizing what students are interested, success in teaching will be achieved. However, the notion of multiple intelligence is culture sensitive because "each culture tends to emphasize particular intelligences" (Hassaskhah, 2009, p. 113).

Thurstone's (1938) theory of primary mental abilities, instead of viewing intelligence as a single, general entity, focuses on seven different primary mental activities including verbal comprehension, reasoning, perceptual speed, numerical ability, word fluency, associative memory and spatial visualization. In the same line, Gardner's (1999) multiple intelligence is also one of the most recent ideas in this regard. To him, numerical expressions of human intelligence do not provide an accurate picture people's abilities. Henceforth, to Gardner, there are nine distinct intelligences that are based on skills and abilities valued within different cultures.

Gardner (1983) identifies the following types of intelligence:

$>\quad$ Verbal/linguistic intelligence allows individuals to make sense of the language through language.

$>$ Logical-mathematical intelligence allows individuals to use, appreciate, and analyze abstract relationships.

$>\quad$ Spatial intelligence enables individuals to perceive visual or spatial information to transform this information, and to create visual images from memory.

$>$ Musical intelligence allows people to create communicate and understand meanings made out of sound.

$>\quad$ Bodily-kinesthetic intelligence entails using all part of the body to solve problems or create products.

$>\quad$ Interpersonal intelligence is the capacity to recognize and make distinctions among others' feelings and intentions, and to draw on these in solving problems.

$>\quad$ Intrapersonal intelligence enables individuals to recognize and distinguish among their own feeling to make decisions about their lives.

$>\quad$ Naturalist intelligence allows solving problems by distinguishing among, classifying, and using features of the natural world.

$>$ Existential intelligence is the capacity to tackle deep questions about human existence, such as the meaning of life, why we die, what our role is in the world.

Gardner's (1999) multiple intelligence considers intelligence as an amalgamation of different components independent of one another, and individuals might have their own weaknesses and strengths in each. As put by Armour-thomas and Gopaul-McNicol (1998), multiple intelligence is based on the conviction that "the human mind is quite modular in design and...separate and independent cognitive process seems to underline the performance on the intellectual tasks" (p. 38).

Along the same vein, Gardner (1983) defines "intelligences as the ability to solve problems or to create fashion products that are valued within one or more cultural settings" (p. 81). Nevertheless, Gardner's multiple intelligence was in conflict with an entity view of intelligence which treats intelligences as fixed and stable. In fact, his view challenges the traditional view of intelligence that a person is equipped with a single capacity that drives logical and mathematical thought. Put differently, Gardner's view towards intelligence is more or less incremental. To him, intelligence is a bio-psychological potential that could be influenced by experience. In fact, 
Shakouri, N., Sheikhy Behdani, R., \& Teimourtash, M.

intelligence is susceptible to change.

Besides, Gardner's multiple intelligence is regarded egalitarian because "no single type of intelligence is viewed as being superior to the others" (Akbari \& Hosseini, 2008, p. 147). In effect, all people, to a certain extent, possess all of these intelligences. Nevertheless, the germination of each intelligence is dependent upon both genetics and social condition. In fact, in Gardner's theory, there seems to be a sporting event between genetics (nature) and experience (nurture).

\subsection{Multiple intelligence domain}

Domain is defined as a socially constructed human endeavor (Gardner, 1999). Henceforth, several intelligences can be applied in the same domain. In this regard, Razmjoo (2008) refers to three domains of multiple intelligence, that is, analytical, introspective, and interactive that can be served as an organizer for exploring and understanding the relationships among the intelligences and how the intelligences work with one another. Similarly, McKenzie (1999) states that each domain has its own sub-branches. The analytic domain includes the musical, logical, and naturalist intelligences; these three intelligences promote the processes of analyzing and incorporating data into existing schema. The interactive domain contains the interpersonal, kinesthetic, and linguistic intelligences; these three intelligences encourage interaction to achieve understanding. The introspective domain includes existential, visual, and intrapersonal intelligences; these three intelligences require a looking inward by the learner, an emotive connection to his/her own experiences to make sense of new learning. The analytical, interactive, and introspective intelligences are by their nature heuristic, social and affective processes, respectively.

\subsection{On the notion of linguistic intelligence}

One of the nine types of multiple intelligences that we refer to the current work is linguistic intelligence that is the most frequent type of intelligence (Estaji \& Nafisi, 2014). Linguistic intelligence refers to the ability to think in words and use the words to communicate one's thought. In sum, the capacity to use words to communicate is a skill that comes from the temporal cortex on the left side of the brain. This area is called Broca's Area responsible for four areas of sensitivity including semantics, phonology, syntax, and praxis referring to the different ways words can be used in a sentence or culturally to invoke different meanings. In a sense, people with a high linguistic intelligence tend to think in words (Nolen, 2003) and that have the ability to use language effectively both orally and in writing (Christison \& Kennedy,1999); that is, those who have a high level of sensitivity to sound, sentence structure, meaning, and illocutionary force (Armstrong,1999) are linguistically intelligent.

Put differently, Gardner (1983) has described linguistic intelligence as sensitivity to spoken and written language and the ability to use language to accomplish goals as well as the ability to learn new languages. Thus, linguistic intelligence includes the ability to persuade others using words, creative writing skills, and the ability to pick up on other languages easily. To Gardner, lawyers, public speakers, writers, and poets possess high levels of linguistic competence since they are equipped with the capacity of verbal comprehension and word fluency. As to Razmjo (2008), verbal comprehension entails the ability to understand the meanings of both individual words and passages of written or spoken texts. Conversely, word fluency involves the ability to generate rapidly many examples of words that meet some specification (e.g., words beginning with a given letter, words rhyming with a target word, words naming objects that have some property, etc.). However, as to several scholars (e.g., Szalontai \& Csiszar, 2013), there exist several genes that contribute to linguistic ability. As Szalontai and Csiszar (2013) state, the NRXN1 gene is linked to general language ability, the mutation of which is believed to affect linguistic intelligence.

\subsection{Recall}

Recall appears to be "a process of constructing a pattern of activation taken by the recaller to reflect not the 
present input to the senses, but some pattern previously experienced" (McClleland, 1999, p. 138). Central to this view, according to McClleland, "is the idea that recall is prone to a variety of influences that often help us fill in missing details but which are not always bound to fill in correct information" (p. 138). Dobinson (1996) declares "vocabulary needs explicit attention in order for it to be noticed and recalled" (p. 39). Moreover, the information that can be integrated with the pre-existing structure in the long-term memory is conducive to an effective recall (Jefferies, Ralph, \& Baddeley, 2004).

Recall is usually divided into two categories namely free recall and cued recall. In free recall, participants are given a list of items learned earlier and then is asked to recall them in any order. Cued recall, in contrast, is the process in which a person is given a list of items to remember and is then tested with the use of cues or guides. Ozubko (2011) declares that the comparison between free recall and cued recall is implausible because "cued recall procedures encourage guessing" (p. 3). In fact, studies (e.g., Bahrick, 1969; Thomson \& Tulving, 1970) have reported that cued recall leads to performance superior to that of free recall.

\subsection{Purpose and research questions}

Concerning what has been brought in the literature, the present researchers attempted to investigate the relationship between linguistic intelligence and recalling lexical items in L2. In so doing, the following research question was raised:

Is there any statistically significant relationship between participants' linguistic intelligence and recalling lexical items in $L 2$ ?

Regarding the research question, the following null hypothesis was formulated:

There is no statistically significant relationship between participants' linguistic intelligence and recalling lexical item in $\mathrm{L} 2$.

\section{Method}

\subsection{Participants}

The research was conducted in a popular language center located in Bandar-e Anzali, Iran. The participants were 40 intermediate students (17males and 23 females). The participants were all young adults of English ranging in age from 16 to 23 .

\subsection{Instruments}

To carry out the present study, three instruments were employed:

$>$ McKenzie's (1999) MI Inventory was used as an established tool to identify the typology of intelligence.

$>\quad$ A cued recall test was also used to measure the participants' recall. To measure, the test reliability, the Cronbach's alpha was employed for this purpose and an acceptable reliability of 0.82 was obtained.

\subsection{Procedure}

Being descriptive, the procedure of the present study, from one side, was limited to the preparation of questionnaires and their administration to the students studied at a popular language center in Bandar-e Anzali. From another side, to check whether participants' linguistic intelligence had any relationship with recalling lexical items in L2, the present researchers designed a post-test. The test was composed of two different lists of L2 lexical items. The first list included 40 lexical items, each of which was categorically related to the cue 
Shakouri, N., Sheikhy Behdani, R., \& Teimourtash, M.

presented. For example, in the given list, the participants would have yellow that was categorically related to color. The second list was semantically related. Semantic relatedness includes any relation between two lexical items. For example, car is semantically related to road and driving. In order to avoid guessing, the researchers acted as follows. After producing a word, a subject could be asked to decide whether that word was either studied or non-studied. That is, subjects could be asked to recognize their own recalls. Indeed, although it may seem redundant at first, such procedures are already commonplace (Angel, Fay, Bouazzaoui, Granjon, \& Isingrini, 2009).

\section{Results and discussion}

Testing null hypothesis - To investigate the null hypothesis, stating that there is no statistically significant relationship between participants' linguistic intelligence and recalling lexical item, the researchers carried out a simple linear regression to predict recalling lexical items in L2 based on linguistic intelligence. A significant regression equation was found $(\mathrm{F}(1,38)=23.71, p<.000)$, with an $\mathrm{R}^{2}$ of .38 . The standardized beta coefficient $(B=0.62, \mathrm{t}=4.87, p<0.05)$ also reveals that the model was significant meaning that linguistic intelligence could significantly predict the candidates' scores on word recall; therefore, the researchers were able to reject the null hypothesis stating that there is no significant correlation between participants' linguistic intelligence and cued recall. Conversely, linguistic intelligence significantly predicted the scores on recall in L2.

The results of paper are compatible with Krueger and Salthouse (2011) who asserted that high level of intelligence was associated with better recall of the last items. They further reported that better performance on recall is highly associated with intelligence. Put differently, higher episodic memory is associated with better recall. Moreover, linguistic intelligence, as to Naseri and Ansari (2013), is respected as the best predictor of the learners' L2 writing achievement. Mahdavi (2008), also, came out to a similar conclusion that linguistic intelligence is a predictor of TOEFL and IELTS listening scores and English language proficiency as well. Similarly, in the study conducted by Samiyan (2013), the result indicated that learners with high linguistic intelligence mostly use comprehension, metacognitive, and affective strategies.

Last but not the least, this finding was specifically in line with Parsa, Jahandar, and Khodabandehlou (2013) who contend that there is a significant correlation between verbal/linguistic intelligence and knowledge of lexicon. Also, their study depicts that the participants who had higher marks in vocabulary tests had high verbal/linguistic intelligence.

\section{Conclusion and implications}

The present study attempted to investigate the question stating whether there is any statistically significant relationship between L2 vocabulary recall and linguistic intelligence. The findings indicate that such a relationship does exist. In practicality, Gardner's multiple intelligences theory can provide a framework for teachers in designing classrooms, instruction, and curricula that meet the individual needs. In other words, helping teachers and students realize that there are multiple ways to learn is but one reason to consider Multiple Intelligences theory as a plausible perspective to fulfill students' needs. Besides, "a person's prominent types of multiple intelligences show not only his capacities but also his favored learning styles" (Naseri \& Ansari, 2013, p. 289). Thus, based on the results reported and the discussion conducted, can be a good predictor of cued recall in L2 context.

Undeniably, learning happens when a person can recall words. Although so little has been carried out regarding the relationship between linguistic intelligence and recalling lexical items in 12 , the present paper felt a need to work on students' linguistic intelligence since it is trainable and changeable. In effect, according to Estaji and Nafisi (2014), linguistic intelligence is the most dominant type used in the young learners' textbooks. Thus, "language textbook should encompass activities highly focusing on the linguistic intelligence type" (p. 68).

Finally, multiple-intelligence theory can provide a flexible approach to plausible teaching. The results of the 
present study allows us to argue for a number of pedagogical implications with respect to the relationship between linguistic intelligence and recall in SLA. The present paper revealed that Iranians' ability to recall words in L2 is partly related to their linguistic intelligence. Henceforth, if their linguistic intelligence is improved, undeniably, their ability to recall gets improved. Nevertheless, the findings of the study need to be treated with caution. The replication of the study is needed to determine the generalizability of the findings.

\section{References}

Akbari, R., \& Hosseini, K. (2008). Multiple intelligences and language learning strategies: Investigating possible relations. System, 36, 141-155. https://doi.org/10.1016/j.system.2007.09.008

Angel, L., Fay, S., Bouazzaoui, B., Granjon, L., \& Isingrini, M. (2009). Neural correlates of cued recall in young and older adults: An event related potential study. Neuro Report: For Rapid Communication of Neuroscience Research, 20(1), 75-79. https://doi.org/10.1097/wnr.0b013e32831b6e0c

Armour-Thomas, E., \& Gopaul-McNicol, S. (1998). Assessing intelligence: Applying bio-cultural model. London: Sage.

Armstrong, T. (1999). Seven kinds of smart: Identifying and developing your multiple intelligences. New York: Penguin Putnarn, Inc.

Bahrick, H. P. (1969). Measurement of memory by prompted recall. Journal of Experimental Psychology, 79(2), 213-219. https://doi.org/10.1037/h0026935

Brown, H. D. (2000). Principles of language learning and teaching (4 $\left.4^{\text {th }} \mathrm{ed}\right)$. New York: Longman.

Christison, M. A., \& Kennedy. D. (1999). Multiple intelligences: Theory and practice in adult ESL. National Clearinghouse for ESL Literacy Education Washington DC (ERIC Digest ED441350).

Dobinson, T. (1996). The recall and retention of new vocabulary from second language lessons (Unpublished master's thesis). Edilh Cowan University.

Ellis, R. (2008). The study of second language acquisition ( $2^{\text {th }}$ ed.). Oxford: Oxford University Press.

Estaji, M., \& Nafisi, M. (2014). Multiple intelligences and their representation in the EFL young learners' textbooks. International Journal of Research Studies in Language learning, 3(6), 61-72. https://doi.org/10.5861/ijrsll.2014.731

Fierros, E. G. (2004). How multiple intelligences theory can guide teachers' practices: Ensuring success for students with disabilities. Villanova University: Villanova University Press.

Gardner, H. (1983). Frames of mind: The theory of multiple intelligences. New York: Basic Books.

Gardner, H. (1999). Intelligence reframed. New York: Basic Books.

Genesee, F. (1976). The role of intelligence in second language learning. Language Learning, 26(2), 267-280. https://doi.org/10.1111/j.1467-1770.1976.tb00277.x

Hassaskhah, J. (2009). There is never any one right way to teach! A case of multiple intelligence. Iranian EFL Journal, 4, 110-133.

Jefferies, E., Ralph, M. A. L., \& Baddeley, A. D. (2004). Automatic and controlled processing in sentence recall: The role of long-term and working memory. Journal of Memory and Language, 51, 623-643. https://doi.org/10.1016/j.jml.2004.07.005

Krueger, L. E., \& Salthouse, T. A. (2011). Influence of cognitive abilities and age on word recall performance across trials and list segments. The American Journal of Psychology, 124(3), 291-300. https://doi.org/10.5406/amerjpsyc.124.3.0291

Mahdavi, B. (2008). The role of Multiple Intelligences MI in listening proficiency: A comparison of TOEFL and IELTS listening tests from an MI perspective. The Asian EFL Journal, 103, 109-126.

McKenzie, W. (1999). Multiple intelligences survey. Retrieved from http://surfaquarium.com/MI/MIinvent.htm

Naseri, E., \& Ansari, D. N. (2013). The relationship between multiple intelligences and Iranian high school students' L2 writing achievement. International Journal of Psychology and Behavioral Research, 2(5), 282-290.

Nolen, J. L. (2003). Multiple intelligences in the classroom. Education, 124(1), 115-120.

Ozubko, J. D. (2011). Is free recall actually superior to cued recall? Introducing the recognized recall procedure 
Shakouri, N., Sheikhy Behdani, R., \& Teimourtash, M.

to examine the costs and benefits of cueing (Unpublished doctoral thesis). University of Waterloo, Toronto.

Parsa, M., Jahandar, S., \& Khodabandehlou, M. (2013). The effects of verbal intelligence on knowledge of lexicon. International Journal of Applied Linguistics and English Literature, 2(2), 114-121. https://doi.org/10.7575/aiac.ijalel.v.2n.2p.114

Piaget, J. (1963). The origin of intelligence in children. New York: W.W. Norton \& Company, Inc.

Ponderator, F. (2007). Individualism. Retrieved from http://www.yourstrawman.com/Individualism.pdf

Razmjoo, S. A. (2008). On the relationship between multiple intelligences and language success. The Reading Matrix, 8(2), 155-174.

Samiyan, L. V. (2013). The relationship between linguistic intelligence and L2 learning strategies among EFL learners with intermediate level of proficiency. Journal of Literature, Language and Linguistics, 1 , 89-93.

Sternberg, R. J. (1984). Beyond IQ: A triarchic theory of intelligence. Cambridge: Cambridge University Press.

Szalontai, A., \& Csiszar, K. (2013). Genetic insights into the functional elements of language. Human Genetics, 132(9), 959-986. https://doi.org/10.1007/s00439-013-1317-0

Tanzeel, C. (2010). The impact of intelligence on second language acquisition. Retrieved from http://dspace.bracu.ac.bd:8080/xmlui/handle/10361/779

Thomson, D. M., \& Tulving, E. (1970). Associative encoding and retrieval: Weak and strong cues. Journal of Experimental Psychology, 86(2), 255-262. https://doi.org/10.1037/h0029997

Thurstone, L. L. (1938). Primary mental abilities. Chicago: University of Chicago Press.

Vygotsky, L. S. (1978). Mind in society. The development of higher psychological process. Cambridge: Harvard University Press. 